\title{
Nutrition-sensitive agriculture: new term or new concept?
}

\author{
Angelina G. Balz , Eleonore A. Heil and Irmgard Jordan
}

\begin{abstract}
Background: Within the post-2015 agenda discussions of the United Nations, sustainable development goals (SDGs) are being drafted. In this context, nutrition-sensitive agriculture has been introduced. Nutrition-sensitive approaches in general are not new. They refer to improving or at least avoiding harm to the underlying and basic causes of malnutrition presented in the UNICEF conceptual framework. In order to answer the question of whether nutrition-sensitive agriculture is only a new term or also a new actionable concept with a comprehensive definition, framework, and political will, a questionnaire-based survey with representatives from 18 agricultural ministries of various countries was conducted on the basis of a literature review. Furthermore, the Final Communiqué of the Berlin Agriculture Ministers' Summit 2014 was analyzed as an indication of political commitment following the steps of the qualitative content analysis of Mayring.

Results: Care was considered less than food security and health in the responses to the questionnaire and was not mentioned at all in the final communiqué. In the survey and the communiqué, mainly health aspects related to food safety and water issues were mentioned. However, the most mentioned aspect regarding food security was diversification/diversity. Because of the small sample size of the survey, the findings cannot be generalized. Nevertheless, together with the analysis of the communiqué, the results give some valuable insight into the interests of agricultural politicians for nutrition-sensitive agriculture and indicate that nutrition-sensitive agriculture has rarely been discussed from a systemic perspective. This is confirmed in the criticism expressed that an opportunity to address nutrition in a multisectoral approach that considers all underlying causes of malnutrition - food insecurity, poor health, and lack of care-was missed during the Second International Conference on Nutrition (ICN2).
\end{abstract}

Conclusions: In conclusion, nutrition-sensitive agriculture seems to be more of a term than a concept at the time of this study. To make ICN2 count in coming years and comprehensively address nutrition through a SDG, a systemic approach and true cross-sector collaboration are needed.

Keywords: Nutrition-agriculture linkages, Food system, Agricultural policy, UNICEF model, Second International Conference on Nutrition (ICN2), Post-2015 agenda

\section{Background}

More than half of the global population is not adequately nourished: hunger, micronutrient deficiencies, overweight, and obesity often exist in parallel in the same country [1]. The nature and causes of malnutrition are complex, and additional challenges such as changing demand for agricultural products as well as climate change and natural resource degradation complicate the situation even more [2,3]. A renewed focus is laid on all these issues through the discussions around the post-

\footnotetext{
* Correspondence: Angelina.G.Balz@ernaehrung.uni-giessen.de International Nutrition, Institute of Nutritional Science, Justus Liebig University Giessen, Wilhelmstrasse 20, 35392 Giessen, Germany
}

2015 agenda and the development of sustainable development goals. In this context, a stand-alone goal for food security and good nutrition is discussed [4]. Different targets should be defined that include ending hunger, reducing the multiple burdens of malnutrition, and sustainable agriculture. Looking at these targets, the question arises as to how they can be achieved. The Second International Conference on Nutrition (ICN2) in November 2014 reviewed the progress made regarding nutrition since the 1992 ICN, the problems that remain, and the new challenges and opportunities for improving nutrition. The outcomes of this conference include a political document, the Rome Declaration on Nutrition, and a 
framework for action that provides a set of voluntary policy options and strategies for use by governments as appropriate. As an inclusive inter-governmental meeting on nutrition jointly organized by the Food and Agriculture Organization (FAO) and the World Health Organization (WHO), it intended to adequately address the major nutrition challenges. The results of ICN2 shall also contribute to the post-2015 UN development agenda mentioned above [5].

In these political processes, nutrition-sensitive approaches to agriculture are considered key to achieving food security and good nutrition. These approaches are not new [6]. While nutrition-specific interventions tackle the immediate causes of malnutrition, e.g., supplementation with micronutrients if nutrient intake is less than needed, nutrition-sensitive approaches refer to improving or at least avoiding of harm to the underlying and basic causes of malnutrition presented in the UNICEF conceptual framework. They seek to improve the context in which nutrition is embedded and by doing so find long-term solutions [6-8]. Therefore, the UNICEF conceptual framework of malnutrition [9] was slightly adapted and served as a basic concept for this study (Fig. 1). It defines three important aspects that have to be considered in order to improve nutrition: food security, care, and the health environment. These underlying causes determine whether the diet is adequate and the person is healthy (immediate causes of malnutrition). The underlying causes themselves are affected by basic causes determined by the social, economic, and political context. Examples for these include the rights of women and girls, poverty, and climate change. The conceptual model is a widely accepted, wellestablished framework and is considered a useful tool to understand which factors are important for nutrition. $\mathrm{Nu}-$ trition is a complex issue where interrelations are often not linear, and distant factors must also be considered. Thus, if interventions or a sector want to be nutritionsensitive, the underlying and basic causes have to be taken into consideration [6,7]. Therefore, the characteristics of nutrition-sensitive agriculture were identified by using this modified UNICEF conceptual framework as a checklist.

In this context, this study seeks to contribute to the ongoing discussion by analyzing whether nutrition-sensitive agriculture is only a new term or also a new concept. Two issues are in focus. First, is there an actionable concept with a comprehensive definition and framework? Second, does commitment exist in agricultural policy for nutrition-sensitive agriculture?

\section{Methods}

On the basis of a literature review, a questionnaire-based survey was conducted with representatives from 18 agricultural ministries of various countries at the Global Forum for Food and Agriculture 2014 in Berlin, where 65 agricultural ministers participated. Moreover, the final communiqué of the Berlin Agriculture Ministers' Summit 2014 was analyzed, following the steps of Mayring's qualitative content analysis $[10,11]$.

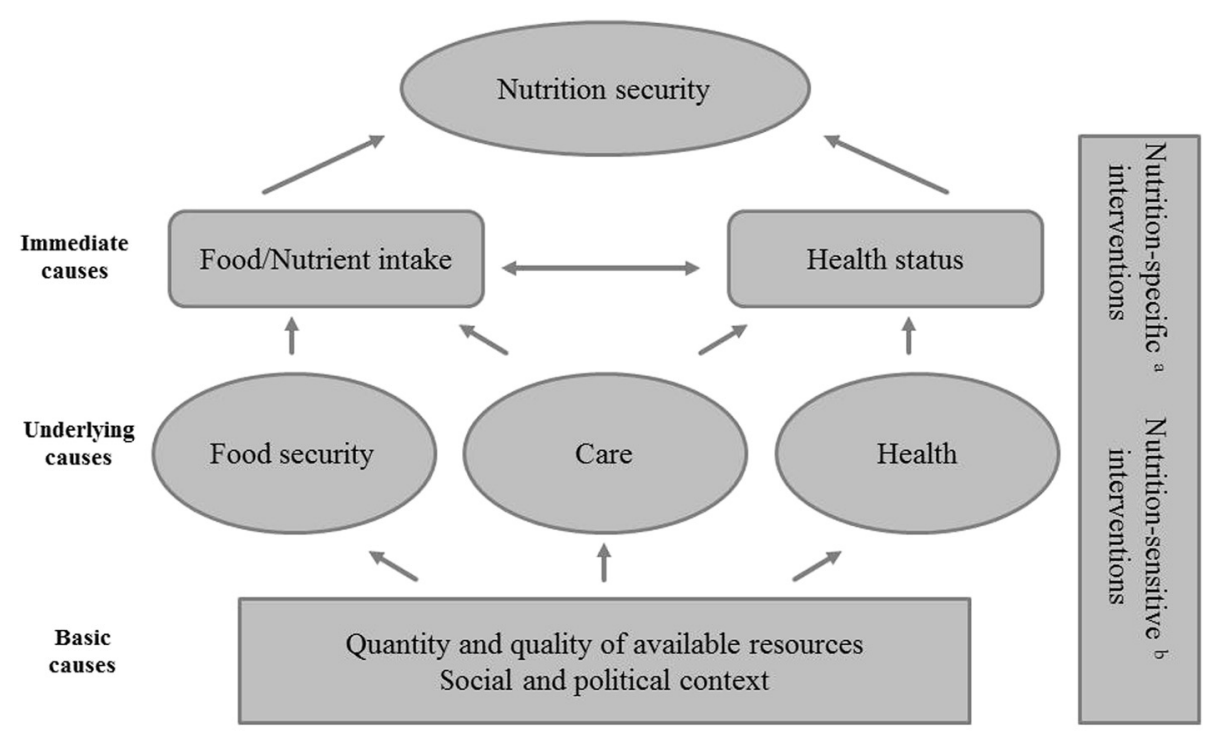

${ }^{a}$ Nutrition-specific interventions tackle the immediate causes of malnutrition, e.g. supplementation with micronutrients.

${ }^{b}$ Nutrition-sensitive approaches refer to improving or at least avoiding of harm to the underlying and basic causes of malnutrition

The transition between a) and b) is fluid.

Fig. 1 Modified UNICEF conceptual framework (own presentation in accordance with $[16,73]$ ) 


\section{Questionnaire-based survey at the Global Forum for Food and Agriculture}

The survey was conducted at the Global Forum for Food and Agriculture (GFFA) in Berlin from 16-18 January 2014. The GFFA is an international conference that is held during International Green Week (IGW) and is organized by the Federal Ministry of Food and Agriculture (BMEL) in cooperation with GFFA Berlin e.V., the Senate of Berlin, and Messe Berlin GmbH each year. In 2014, it took place for the sixth time. Representatives from politics, business, science, and civil society used the forum to meet, share ideas, and enhance political understanding on central issues in the future. The 2014 topic was "Empowering Agriculture: Fostering Resilience-Securing Food and Nutrition" [12]. During the first 2 days, there were expert panel discussions on aspects of the main topic. On the second day, four working sessions were organized by the international organizations FAO, EU-Commission, World Bank, and United Nations Environment Programme (UNEP). The third day was the most important one; here, the International GFFA Panel Discussion was held, and in the afternoon, the Berlin Agriculture Ministers' Summit took place (Fig. 2).

The GFFA was chosen because it is the worlds largest conference of agricultural ministers, with 65 ministers in 2014. Additionally, the working session of the FAO focused on "food systems for better nutrition", in which the participants discussed nutrition-agriculture linkages. The results of this and the other three working sessions were included in a final communiqué. The communiqué is the outcome of the summit and represents the common position of the participating ministers. They committed to incorporating it into the ongoing international discussions on agricultural policy such as ICN2 and the post-2015 process [12].

The target group of the survey were the ministers and representatives of the agricultural ministries participating at the GFFA. A standardized questionnaire was presented directly to them for self-administration. Participants gave informed consent before taking part. Ethical approval was not needed because social research, not medical, was conducted.

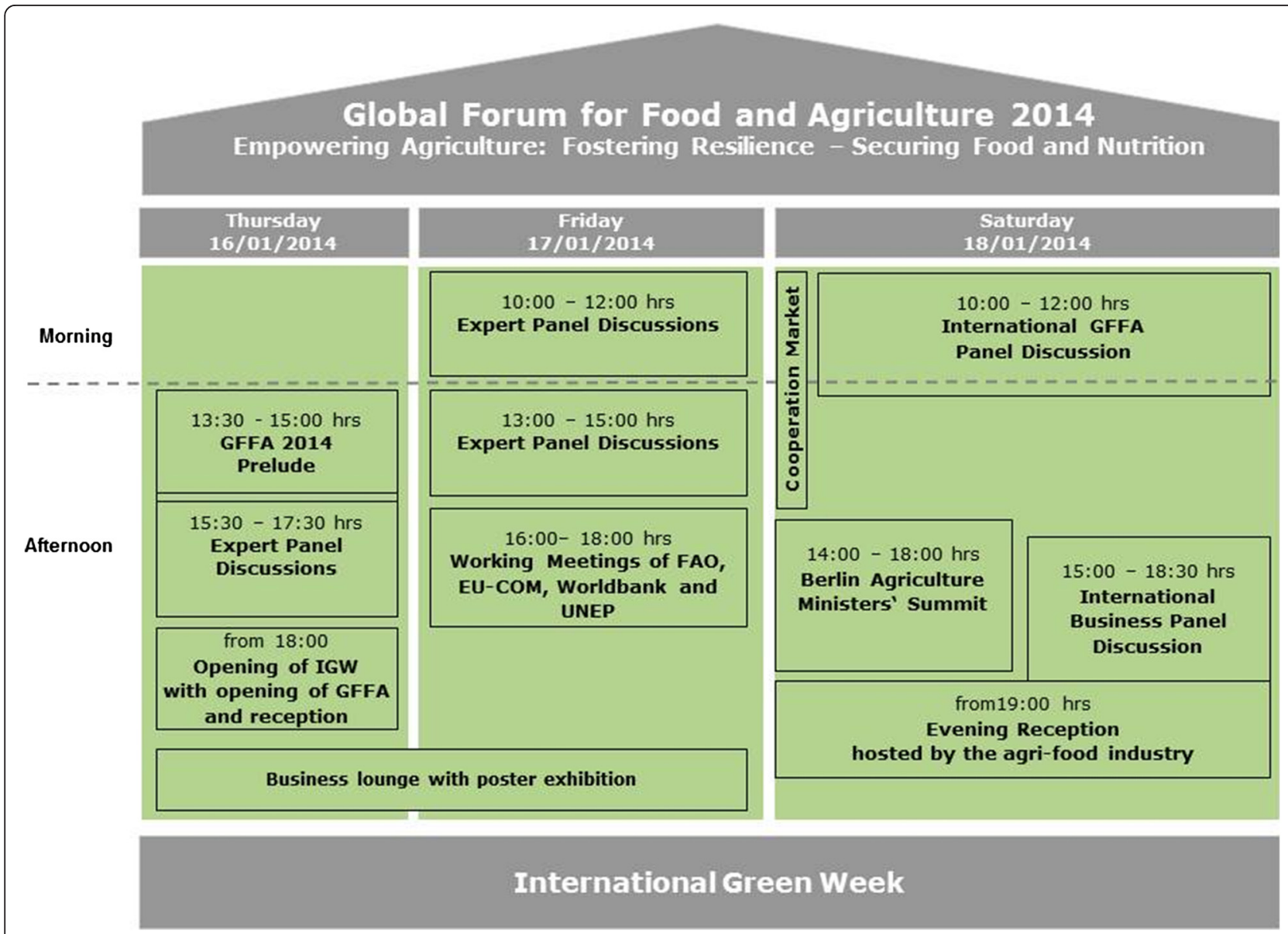

Fig. 2 Structure of the Global Forum for Food and Agriculture 2014 [12] 


\section{Content and design of the questionnaire}

Three main items were of primary interest for the survey: first, the prominence of the concept, if countries are already aware of it or have implemented it; second, what their understanding of the concept is; third, the added value of the concept was examined by looking at its aim, its usefulness with regard to nutrition security, and its relationship to the right to food.

The questionnaire (see Additional file 1) was designed based on a literature review where papers published in journals and publications of international organizations were included. Peer-reviewed papers were searched primarily in the databases PubMed, CAB Abstracts, and Web of Science. The webpages of international organizations relevant to the field of agriculture as well as food and nutrition security were searched for nutrition-sensitive agriculture-related publications. Important sources were the webpages of the Food and Agriculture Organization of the United Nations (FAO), International Food Policy Research Institute (IFPRI), the World Bank, and the United Nations Standing Committee on Nutrition (UNSCN). Searches were mainly conducted between November 2013 and February 2014. The keywords used were nutrition-sensitive/nutrition-enhancing/nutrition-smart/nutrition-focused agriculture, promoting/improving nutrition through agriculture, linking agriculture and nutrition/ health, nutrition-agriculture linkage, and agriculture for nutrition. To minimize the risk of missing relevant papers, reference lists of key studies were reviewed for additional relevant studies. Only the most recent literature that had been published between 2008 and 2014 was included. Papers were excluded that did not refer to agriculture as a nutrition-sensitive sector or that focused only on a single problem, e.g., aflatoxin and stunting. Only publications in English were used for further analysis.

There was no commonly agreed upon definition for nutrition-sensitive agriculture found in the literature. Moreover, no conceptual framework could be found that explicitly described what nutrition-sensitive agriculture looks like. Therefore, four definitions and six aims found in the literature were cited directly or in a modified fashion [13-17]. Most reviewed publications (90 \%) referred to food security, in particular to diversification (82.5\%), less so to health $(57.5 \%)$, and rarely to care $(37.5 \%)$. There was no agreement in the literature about the most appropriate foods and production systems. Nevertheless, sustainable forms of agriculture were frequently mentioned. The most important cross-cutting issues were gender equity, nutrition education for all actors along the value chain, and collaboration between agricultural, nutritional, and health professionals [2, 7, 8, 13-50].

In the questionnaire, cross-sectoral factors and elements that should be included in the concept of nutrition-sensitive agriculture for nutrition security, food security, health, and care were surveyed. Furthermore, the representatives should specify which foods in their opinion should be the focus of nutrition-sensitive agriculture and which production system would be most appropriate for it. For each question, the issues were cited that were mentioned in the reviewed publications. The modified UNICEF model served as the basic structure for the arrangement of the questions. The questions had to be answered quickly and easily, since ministry representatives do not have much time to fill out questionnaires. Therefore, it consisted only of 18 closed questions covering five pages.

\section{Pretest}

Students of nutritional science and other academic backgrounds examined the questionnaire for clarity and assessed its duration. Normally, about $15 \mathrm{~min}$ were needed to complete the questionnaire. After including the students' comments, which were mainly on understanding and wording of the questions, the questionnaire was given a second time to employees of Division 622-World Food Affairs of the German Ministry of Food and Agriculture. One important issue that was raised was the distinction between food security and nutrition security found in two questions (questions 10 and 11). These two terms were not considered to be accepted worldwide as different terms, and comprehension of these was not clear. Definitions were given before they appeared in questions, and they were arranged according to the modified UNICEF model, starting with the comprehensive term nutrition security and followed by the three main aspects food security, care, and health. Another aspect was the right to food. To secure a common understanding of the right to food, the definition was given before the question.

\section{Dissemination of the questionnaire}

The questionnaire was disseminated at the GFFA to as many representatives of the delegations as possible. The procedure was twofold. First, questionnaires were placed in the business lounge where only the delegations had access and at relevant expert panel discussions and working meetings, namely, the kick-off event, the expert panels on "Opportunities for better nutrition along agricultural value chains: building on learning from rice in Bangladesh" and on "Horticultural contributions to the fight against malnutrition", and the working session of the FAO about "Food systems for better nutrition". Second, the study was presented by the author and the study team to the delegations. They asked the delegates to answer the questionnaire on site and send it back via e-mail or to give their contact data in order to receive the questionnaire via e-mail at a later date. At the GFFA, 100 questionnaires were printed and disseminated in 
hardcopy. This number was chosen based on estimates that about one third would get lost by delegates that took two copies or by not-targeted visitors of the events. On the last day of the summit, the strategy of presenting the study and collecting contact data was more strongly pursued.

As a follow-up, the questionnaire was sent to the collected contact addresses via e-mail. Before sending, it was converted into Word format with text boxes, check boxes, and drop-down lists in order to allow electronic administration. Delegations that had no embassy in Berlin received support at the GFFA through volunteers from the BMEL. These were asked to inform the delegations about the research project and distribute the questionnaire to each representative. After the GFFA, the BMEL staff members who were in charge of the delegations were reminded of the study and asked to send the questionnaire via e-mail again. As a second strategy, other networks were used, e.g., personal contacts to representatives of European Member States were asked to answer the questionnaire. Moreover, the German agricultural attachés in the countries were asked to informally disseminate the questionnaire to their contacts in the agricultural ministries. The first deadline was the 31 January 2014. This was later pushed back to the end of February 2014. Delegates who had pledged to return it but had not up to this point were asked again. By the end of March, data collection was concluded.

\section{Data analysis}

The data of the questionnaire were coded, entered into a Microsoft Excel spreadsheet, and converted into a pivot table. A descriptive analysis was made, frequencies were shown, and sub groups analyzed with cross tables [51]. The data were finally transferred into SPSS 11.5 for further cross tabulations, statistical tests, and cluster analysis. Statistical significance tests were only made in some cases to confirm suggestions. The $p$ value was defined as the probability of the observed data, given that the null hypothesis $H_{0}$ is true. This contains very limited information. The rejection of a null hypothesis is no basis for estimating the probability that in a replication of the research the null hypothesis will also be rejected [52]. Therefore together with the $p$ value, the effect size phi was reported in order to improve interpretation of the collected data. Effect sizes do not take sample size into account and are therefore independent of the number of participants [53]. Phi is similar to the correlation coefficient; in fact, if both variables are dichotomous, Pearson's $r$ is equal to phi. Correlations between 0.2 and 0.5 were interpreted as medium sized according to the rules for social science data analysis of Kühnel and Krebs [54]. The cluster analysis was conducted using Ward's method in order to see whether specific groups could be found.
Ward's method was used because it clusters the results according to the smallest variance within a cluster.

The question about which foods should be in the primary and secondary focus of nutrition-sensitive agriculture was analyzed in two ways: The questionnaires that were filled out as intended were analyzed together. Frequencies were given to all the answer possibilities as a whole and divided by focus. A secondary analysis was made for the questionnaires that were not filled out as intended. In an initial step, we examined food options that were not considered at all. Then, the other foods were classified as primary or secondary according to the most frequently given answer.

\section{Analysis of the Final Communique of the GFFA 2014}

The Final Communiqué of the GFFA 2014 was analyzed as an indication of the political will and confirmation to implement the concept of nutrition-sensitive agriculture. The first draft of the communiqué was developed by a group of experts from the BMEL in a consolidated process. After completing an initial draft, it was sent to four international organizations, FAO, EU-Commission, UNEP, and World Bank, for further changes and comments. After these were included, the registered Ministries of Agriculture added their comments, which were also included in the final draft and approved by the German Minister of Food and Agriculture. At the Berlin Agriculture Ministers' Summit, the process was opened again for a 4-h discussion. After reaching a consensus on the communiqué, all 65 participating ministers approved and signed it (own observations). The final communiqué was chosen because the results of the working sessions of the international organizations should be considered in the declaration. The working sessions of FAO concentrated on "food systems for better health". The session discussed the issues of how to maximize the contribution of agriculture and food systems in order to improve nutrition.

For the analysis, the English version of the Final Communique of the GFFA 2014 was used by following the steps of the qualitative content analysis of Mayring (see Fig. 3). The qualitative content analysis according to Mayring is a mixed methods approach that actually contains both qualitative and quantitative analytical steps. The central idea of qualitative content analysis is to start from the methodological basis of quantitative content analysis (analysis of category frequencies) and then conceptualize the process of assigning categories to text passages as a qualitative-interpretive act, following content-analytical rules. Therefore, it follows a step-by-step model for the research process. Because analysis and interpretation is based on content-analytical rules that are defined in advance, reliability is increased $[10,11]$. This method is appropriate for analyzing the communiqué because it is a method for investigating 


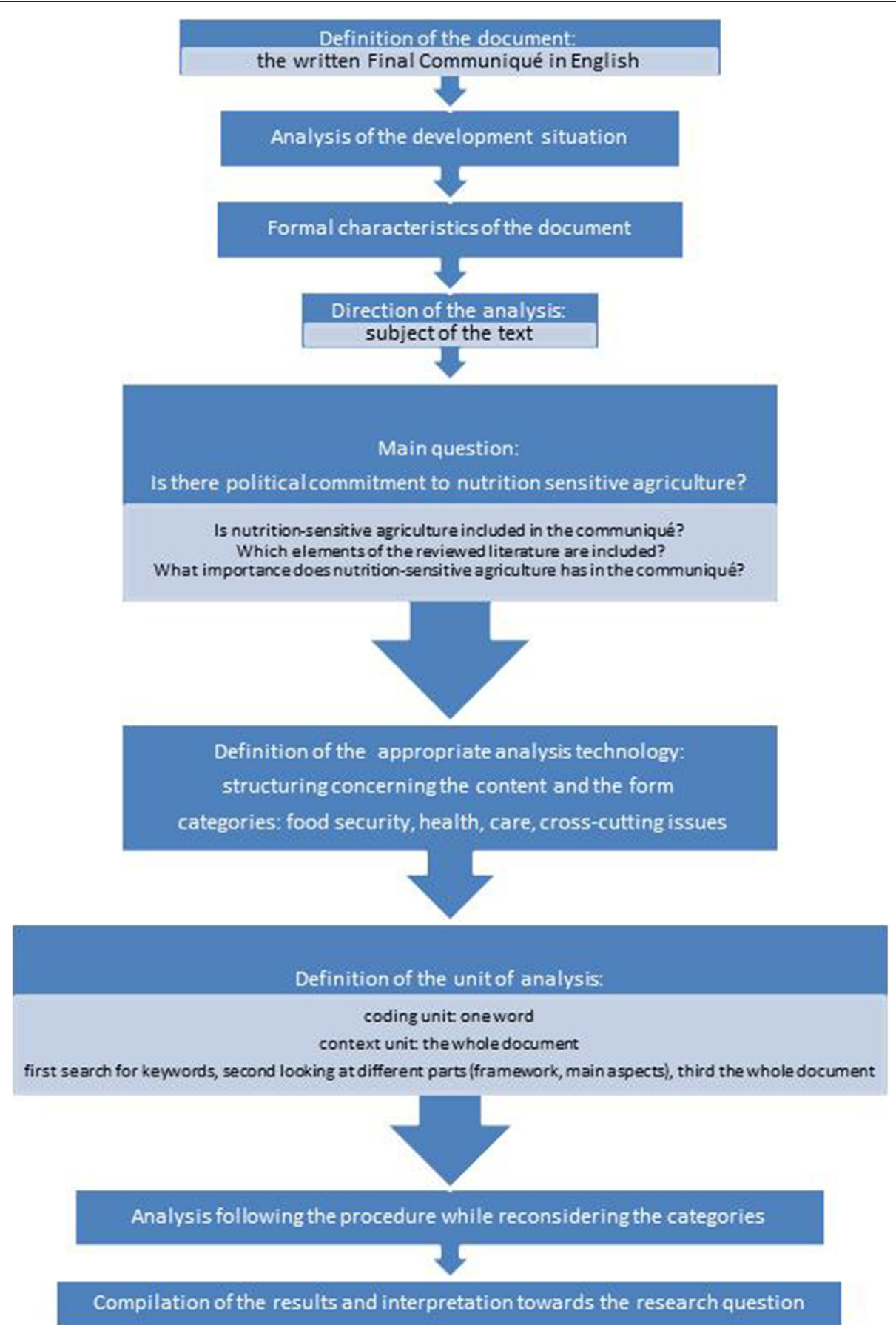

Fig. 3 Qualitative content analysis procedure (own presentation in accordance with [10, 11])

statements that are made consciously and explicitly. Moreover, through this technique, the text is interpreted within the communicative context. Both are important aspects for analyzing a political statement with a clear research question.

The focus of the analysis of the communiqué was the subject of the text. The main research question of the content analysis was whether there is political commitment to implement nutrition-sensitive agriculture. Therefore, three sub-questions were defined:

- Is the topic nutrition-sensitive agriculture included in the communiqué?

- Which elements of the reviewed literature are included?

- What importance does nutrition-sensitive agriculture has in the communiqué? 
Specific aspects regarding nutrition-sensitive agriculture were filtered out of the communiqué, and their importance was analyzed by looking at the frequency and structure of the communiqué (structuring concerning the contents and the form). Categories were defined deductively and inductively based on the modified UNICEF model and the reviewed literature: food security, health, care, and cross-cutting issues (e.g., gender, sustainability, education, and collaboration, as well as environmental, economic, political, and social contexts). The unit of analysis was defined: one word was the smallest unit (coding unit), and the whole document was the biggest unit (context unit). We first searched for keywords in the document, then, the framework and the three main aspects of the communique were analyzed, and finally, the whole document was examined. The analysis was made following the described procedure while reconsidering the categories. A category was broadened if aspects seemed strongly related to those described in the reviewed literature and yet were not reflected accordingly in the existing categories. The categories were mainly reconsidered while holistically analyzing the framework and the three main aspects of the communiqué.

\section{Results}

Prominence, content, and value of nutrition-sensitive agriculture as indicated in the survey

At the end, 18 out of 20 questionnaires could be used for data analysis. Two of the 18 questionnaires were filled in incompletely but were nonetheless included in the analysis. Most people who completed the questionnaire were political or technical advisors (7 out of 18). Of the rest, three were scientists, two ministers, and two section chiefs. Most respondents had a professional background in agricultural science (10 out of 16). The others had a background in politics, veterinary medicine, development economy, business administration, and diplomacy.

The main characteristics of the countries of the representatives that filled out the questionnaire are shown in Table 1. The study participants came from Europe $(N=6)$, Africa $(N=5)$, or Asia $(N=7)$. North America, South America, and Australia were not represented in the survey. Eleven of the representatives were from developing countries, and 7 were from industrial countries. No malnutrition problems were assumed for any industrial countries with a representative participating in the study [2]. In six of the developing countries, stunting and micronutrient deficiencies existed; in two of them, all

Table 1 Countries classified according to development status and malnutrition problems

\begin{tabular}{|c|c|c|c|c|c|}
\hline Continent & Country & Stunting & Micronutrient deficiencies & Obesity & No presumable malnutrition problems \\
\hline \multicolumn{6}{|c|}{ Developing countries } \\
\hline \multirow[t]{5}{*}{ Africa } & Burkina Faso & $x$ & $x$ & & \\
\hline & Cameroon & $x$ & $x$ & & \\
\hline & Lesotho & $x$ & $x$ & & \\
\hline & Sierra Leone & $x$ & $x$ & & \\
\hline & Swaziland & $x$ & $x$ & $x$ & \\
\hline \multirow[t]{5}{*}{ Asia } & Armenia & $x$ & $x$ & $x$ & \\
\hline & Malaysia & & $x$ & & \\
\hline & Palestinian Territories & & $x$ & $x$ & \\
\hline & Philippines & $x$ & $x$ & & \\
\hline & Vietnam & $x$ & $x$ & & \\
\hline Europe & Bosnia and Herzegovina & & $x$ & $x$ & \\
\hline \multicolumn{6}{|c|}{ Industrial countries } \\
\hline \multirow[t]{2}{*}{ Asia } & Japan & & & & $x$ \\
\hline & Singapore & & & & $x$ \\
\hline \multirow[t]{5}{*}{ Europe } & Belgium & & & & $x$ \\
\hline & Finland & & & & $x$ \\
\hline & France & & & & $x$ \\
\hline & Italy & & & & $x$ \\
\hline & Netherlands & & & & $x$ \\
\hline
\end{tabular}

Classification of development status according to DAC [74]. Classification of malnutrition problems according to FAO [2]. Data of Palestinian Territories according to the WHO report at the Sixty-sixth World Health Assembly [75] 
three malnutrition problems were present; in two, micronutrient deficiencies and obesity existed; and in one, there were only micronutrient deficiencies.

Out of 17 representatives (only 17 representatives completed the first question), 12 have heard of the term nutrition-sensitive agriculture, but only 7 out of these 12 had read about it in scientific literature. Out of the 12, 3 representatives had attended conferences and/or scientific meetings on this topic and 4 representatives said they had their own internal concept of nutrition-sensitive agriculture. A lack of common understanding of nutrition-sensitive agriculture was the only reported obstacle that hindered them from implementing nutrition-sensitive agriculture. Representatives from seven countries gave reasons other than the choice of answers provided. There was a tendency to consider nutrition-sensitive agriculture basically useful, necessary for nutrition security, and complementary to the right to food. Two of the definitions and aims provided were most frequently chosen (see Table 2).

A medium to strong correlation between development status and definition (phi $\approx 0.41)$ as well as between development status and aim $(\mathrm{phi} \approx 0.42)$ could be found. Developing countries tended to focus more on foodoriented statements, while industrial countries tended to emphasize more system-oriented statements. This correlation was not statistically significant. None declared sustainable diets or combating undernutrition and micronutrient deficiencies while not considering overnutrition as an aim of nutrition-sensitive agriculture. There was no agreement on specific aspects of nutrition-sensitive agriculture such as the most appropriate production system and foods. Diversification and education, in particular nutrition education were seen as essential. Furthermore, collaboration of professionals in agriculture, nutrition, and health was seen as an important cross-sectoral factor and as an important nutrition security element by 15 and 14 representatives out of 18, respectively. Land tenure, culture, environment, value chain, and policy coherence were considered by one to two thirds of the representatives. Sustainable agriculture was seen as an element that should be included in the concept regarding nutrition security by ten representatives, seven of which were from developing countries. A similar result was observed for the factor environment. Both factors tended to correlate moderately to strongly with each other ( $\mathrm{phi} \approx 0.43$ ), but the result was not statistically significant. Of the three pillars of the modified UNICEF model, care was considered significantly less in the context of nutrition-sensitive agriculture than food security or health (Mc Nemar, $p=0.006$ for food security and $p=0.004$ for health) (see Fig. 4). The related factor gender equity was seen by 9 representatives as an important element of nutrition security and by 11 as important cross-sectoral factor.

After analyzing the elements of each pillar of the UNICEF model in detail, some results should be highlighted. No representative stated that nutrition-sensitive agriculture means to diversify the production and consumption of foods. But almost all (17 out of 18) agreed that diversification is an element that should be included in the concept of nutrition-sensitive agriculture. In contrast, only four representatives considered specializing in single nutrientrich crops. Eleven representatives identified agricultural tools such as bio-fortification or micronutrient-enriched fertilizers as important for a concept, and 5 of these considered nutrient bioavailability to be important. Classic elements of food security such as income generation, increasing production, and reducing post-harvest losses were included by about two thirds of the representatives. One representative added access to nutrients as a crosssectoral factor as well as an element of nutrition and food security. The question about the kind of foods that should be the focus of nutrition-sensitive agriculture was only partly filled out as intended. Four representatives assigned all of the possible answers to primary or secondary focus instead of choosing only one answer as primary and one

Table 2 Countries' agreement on definitions and aims of nutrition-sensitive agriculture

\begin{tabular}{lcc}
\hline Definitions and aims & Number \\
\hline Definition & DC (N=11) & IC (N=6) \\
$\begin{array}{l}\text { Nutrition-sensitive agriculture explicitly incorporates nutrition objectives and indicators into agriculture and } \\
\text { addresses the utilization dimension of food and nutrition security, including health, education, economic, } \\
\text { environmental, and social aspects [13]. }\end{array}$ & 4 \\
$\begin{array}{l}\text { Nutrition-sensitive agriculture ensures the year-round availability and accessibility of a variety of diverse foods and } \\
\text { prevents nutrient losses, so that when consumed, these foods improve nutrient intake through dietary diversification, } \\
\text { improve levels of nutrition, and prevent macro- and micronutrient deficiencies [14]. }\end{array}$ & 7 \\
$\begin{array}{l}\text { Aim } \\
\text { Nutrition-sensitive agriculture aims to maximize the impact of the food and agricultural sector on nutrition outcomes } \\
\text { while minimizing the unintended negative nutritional consequences of agricultural interventions and policies along } \\
\text { the value chain from farmers to consumers (modified from World Bank [16]). }\end{array}$ & 3 \\
$\begin{array}{l}\text { Nutrition-sensitive agriculture aims to narrow the gap between available and accessible food and the food needed for } \\
\text { a healthy and balanced diet for all people [13]. }\end{array}$ & 5 \\
\hline$D C$ developing countries, $I C$ industrial countries (classification of development status according to DAC), $N$ number of representatives who answered the question
\end{tabular}




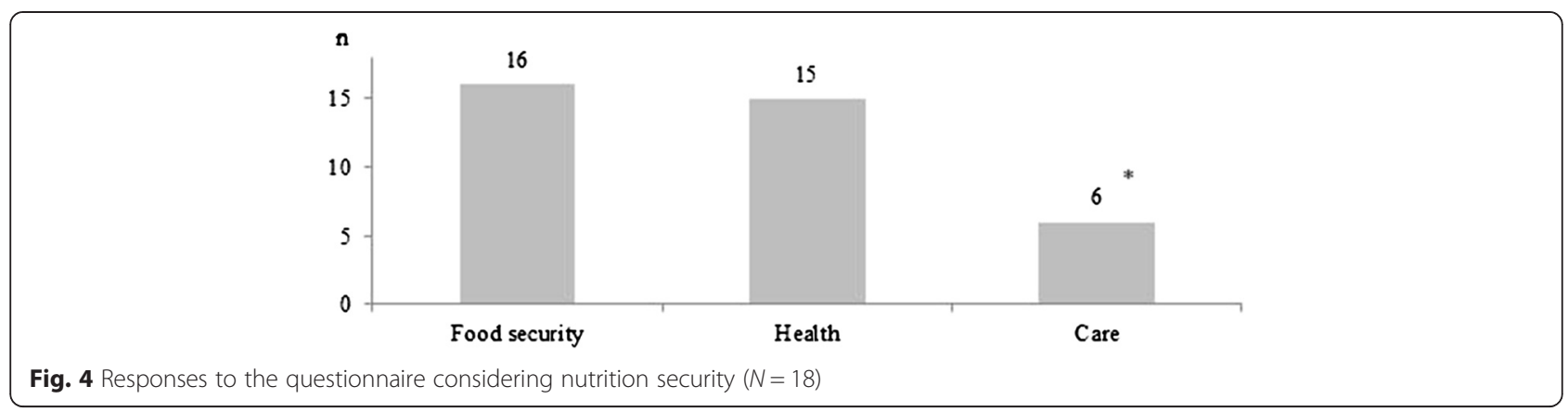

as secondary. A consensus could not be reached in this question. None of the representatives saw (small-scale) animal foods or wild/collected foods as foods in the focus of nutrition-sensitive agriculture. Locally adapted varieties of food were emphasized regardless of the way the question was answered. Fruits and vegetables were considered solely a primary focus (see Table 3 ).

Health aspects seen as most relevant in the context of nutrition-sensitive agriculture were food-associated diseases, water pollution, and health hazards due to the use of chemicals. Vector-borne diseases such as malaria were highlighted by four representatives. About $40 \%$ of the representatives considered zoonotic diseases and the management of natural resources as health aspects (see Table 4).

In terms of care, 13 out of 17 representatives that completed this question considered empowering women and the impact of agriculture on women's income to be important, while the impacts on men's time and income were identified by 4 and 5 representatives, respectively. All 17 representatives identified at least one of the three aspects found in the literature (women's time, women's income, and empowering women) as an important element of care (see Table 5). There were no differences in the answers if care was seen as a substantial element of nutrition security (Kendall's tau-c; $p=0.606$ ). Moreover

Table 3 Frequency of food security elements $(N=18)$

\begin{tabular}{ll}
\hline $\begin{array}{l}\text { Which elements do you think should be included in the } \\
\text { concept of nutrition-sensitive agriculture for food security? } \\
\text { (multiple answers possible) }\end{array}$ & Frequency \\
\hline Diversification & 17 \\
Reduce post-harvest losses & 13 \\
Increased production & 13 \\
Income generation & 12 \\
Agricultural tools (biofortification, & 11 \\
micronutrient-enriched fertilizer) & \\
Soil fertility & 9 \\
Marketing of nutrient-dense foods & 7 \\
Nutrient bioavailability & 6 \\
Specialization in single nutrient-rich crops & 4 \\
\hline
\end{tabular}

no differences could be found between the answers of representatives of developing and industrial countries (Kendall's tau-c; $p=0.687$ ).

The grouping showed that clusters according to development status, participation in the Scaling Up Nutrition (SUN) movement or existing malnutrition problems could not be found throughout the cross-sectoral factors and the elements of nutrition security, food security, health, and care. Moreover, including the answers to the definition and aim could not result in clusters for development status, participation in SUN, or existing malnutrition problems.

\section{Political commitment as expressed in the Final Communiqué of the GFFA}

The Final Communique of the GFFA 2014 was the political outcome document of the summit and represented the common position of the participating ministers. The aim of the Agriculture Ministers' Summit was to discuss and find a common position on important future issues of the food system. The topic of the communique in 2014 was "Empowering Agriculture: Fostering Resilience-Securing Food and Nutrition". It was five pages long and was structured into three main aspects within a framework. The term nutrition-sensitive agriculture was not used in the communiqué. The most mentioned aspect of nutrition-sensitive agriculture therein was diversity (ten hits), which was called one of the three fundamental pillars of developing an efficient, adaptable, and resilient agricultural sector. The

Table 4 Frequencies of elements regarding health $(N=18)$

\begin{tabular}{ll}
\hline $\begin{array}{l}\text { Which elements do you think should be included in the } \\
\text { concept of nutrition-sensitive agriculture to consider health? }\end{array}$ & Frequency \\
(multiple answers possible) & 14 \\
\hline Food-associated disease & 13 \\
Water pollution & 12 \\
Health hazards through the use of chemicals & 8 \\
Zoonotic diseases & 7 \\
Management of natural resources & 4 \\
Vector-borne diseases &
\end{tabular}


Table 5 Frequencies of elements regarding care $(N=17)$

\begin{tabular}{ll}
\hline $\begin{array}{l}\text { Which elements do you think should be included in the } \\
\text { concept of nutrition-sensitive agriculture to consider care? } \\
\text { (multiple answers possible) }\end{array}$ & Frequency \\
\hline Empowerment of women & 13 \\
Impact on women's income & 13 \\
Impact on women's time burden & 9 \\
Impact on men's income & 5 \\
Impact on men's time burden & 4 \\
\hline
\end{tabular}

focus of this aspect was on food security, in particular on availability and the supply side. The main elements mentioned were the diversity of production and breeding. Among the eight specific aspects in the box under the pillar of diversity, one aspect was related to dietary diversity and nutritional needs.

Nutritious or healthy foods were mentioned three times and the production of a diverse range of foods once. All of these hits were in the introductory parts of the first two pages and were mentioned in the context of supply and access together with a call for safe foods. The management of natural resources (five hits) and sustainable agriculture (three hits) was also heavily emphasized. Soil, water, and climate change were mentioned as the same important issues as in the reviewed literature, with water having the most hits (six hits). However, the link to nutrition, in particular health aspects, was not made. All three pillars of sustainability were mentioned, but the aspects regarding sustainable agriculture focused mainly on the environmental dimension. The exception was the last point concerning the Voluntary Guidelines on the Responsible Governance of Tenure of Land, Fisheries, and Forests. The productivity pillar was closely linked to the sustainability pillar. A focus was laid on sustainable intensification in agriculture while increasing efficiency by reducing post-harvest losses. In the last point of the box under the pillar productivity, a link was made to food safety and ecosystem health. Apart from that, the focus was on expertise in production and responsible investment. The third most mentioned issue in the communique was access (six hits) and a rightsbased approach (six hits). In the framework as well as in the boxes of all three pillars, related aspects were mentioned.

In summary, despite the explicit goal of securing food and nutrition to eradicate hunger and malnutrition, respectively, as well as the promotion of an integrated cross-sectoral policy approach, the specific commitments still focused on availability and the supply side. Diet quality, sustainable diets, or the aim to improve the population's nutritional status and therefore health were not included. Of the three underlying causes in the modified UNICEF model, only food security was explicitly mentioned. Health aspects could scarcely be found (five times in five pages) and were only linked to food safety and water issues. The call for establishing healthy food systems on page 5 was not further explained. Care was not mentioned at all.

\section{Discussion}

Low political commitment to nutrition-sensitive agriculture Motivation to take time to participate in the survey was low. This can be seen as an indicator that there is not much interest in the concept and that agricultural ministries do not currently see it as a priority. The low commitment expressed in the final communique of the GFFA generally confirms this hypothesis. Under the headline resilience, the aspect "food systems for better nutrition" lost its relevance in the communiqué. Despite the aim of eradicating hunger and malnutrition, the commitments were scarcely linked to nutrition or seriously considered to the end of the value chain, i.e., to the consumer. Only diversity was included as an aspect, probably because it encompasses a win-win approach that, alongside the potential to benefit to the nutrition and health of the population, increases the resilience and adaptability of agriculture to a changing environment. At least, the term food system was included at two points: at the beginning and end. This can be interpreted as a growing political understanding that the whole value chain has to be considered and that agriculture is embedded and integrated into it.

There are only limited data available to indicate the political commitment to nutrition. Recent progress in transparency has been made by developing the Hunger and Nutrition Commitment Index (HANCI) [55]. The HANCI compares the performance of countries on their political commitment to reduce hunger and undernutrition relative to each other [56]. For 45 developing countries and 23 donor countries, the commitment was assessed and a ranking was established. Only seven developing countries had a high commitment according to the HANCI, while the majority of countries (62\%) had a low or very low commitment (28 out of 45 countries). Of the donor countries, five led on commitment, while ten countries (43\%) had a relatively low commitment [57]. The commitment to hunger reduction and the commitment to nutrition were only weakly correlated. The advantage of the HANCI is that it not only includes rhetorical indicators but also represents action as expressed in legal frameworks, policies and programs, and public expenditures [56]. As the HANCI is a relative index and includes indicators that encompass not only agricultural policy commitment but also political commitment in general and that focus on the reduction of only hunger and undernutrition, it cannot directly be related to the results found here. Nonetheless, both study results showed 
the same tendency: there is room for improvement in political commitment to nutrition.

\section{Consideration of all underlying determinants of malnutrition, especially care aspects}

The political understanding and commitment of agricultural ministries, especially toward "care", were scarce. In the literature about nutrition-sensitive agriculture, the most discussed links to care were the time burden women face, which affects child care and thus child health and nutritional status $[28,35]$. This aspect was only considered by half of the countries that participated in the survey. However, Jones et al. [58] analyzed the time issue in Bolivia and came to the conclusion that one of the most relevant barriers to improved child care was the agricultural livelihood. The results from Bolivia indicate that agricultural production challenges "care", and the role of women in agriculture may be the critical obstacles to improved child feeding. The time and ability of women to provide adequate child care was limited by time spent on agricultural activities such as moving to and from different pastures, chasing straggler sheep, and passing through difficult terrain. Mothers from households with more farmland reported less time available for child care. This indicated that increased agricultural productivity may result in less maternal caregiving capacity in locations where women were responsible for crop maintenance [58]. Also in a newer study, the total amount of agricultural land was negatively associated with child feeding practices. These findings underscore the fact that high agricultural labor burdens for women are a considerable barrier to improving child care and thus the nutrition of infants [59]. A study in Kenya analyzing the implications of dairy production intensification at household level on mothers' infant and young child feeding (IYCF) practices came to a similar conclusion: optimal IYCF practices were adversely affected by higher levels of dairy production. The authors suspected that intensifying work loads of mothers and food insecurity may lead mothers to think they cannot adequately feed their infants through exclusively breastfeeding [60]. Furthermore, in subsistence regions, more diverse farms were associated with better feeding practices [59]. Farmers' crop choices, management practices, and the harsh highland environment decreased agricultural production efficiency and diversity. Food production has been mainly dependent on only one or two crops, which was reflected in the potato-based diets. With a limited diversity in agricultural production, families were frequently unable to improve complementary foods for children by diversifying potato-based meals with others such as fruits, vegetables, or legumes [58]. These findings clearly demonstrate the trade-offs between agricultural labor and child feeding. Jones et al. [58] concluded that to reallocate the time women saved through improved efficiency, caregiving environments have to be transformed and time use decisions have to be guided toward child and maternal care. The context should be properly assessed in order to provide the right incentives that generate win-win situations, wherein efforts to improve the agricultural livelihoods of women may also contribute to improved nutritional status of children. Moreover, men also have to be involved. They are interested in increasing the productivity of their family farm and in supporting the proper care of their children, thus ensuring their contribution to the household through future labor and income. However, a key barrier in Bolivia was a lack of support from husbands. Therefore, the importance of the linkages between agriculture and maternal/child care has to be communicated to the entire household. Shared goals, values, and priorities such as securing a consistent income, maintaining a productive farm, or raising a healthy family should be emphasized [58].

Other care aspects such as advertising and promoting breast milk substitutes or expensive manufactured weaning foods that may lead families to poorer diets at higher cost were not discussed in the literature about nutrition-sensitive agriculture. Moreover, westernization and modernization may suggest that canned baby foods are superior to home-prepared foods or that salt and sugar comprise a better treatment for mild diarrhea than family soups and breastfeeding. Furthermore, working away from home in agriculture or the food system may cause the mother to be separated from her infant for long periods [61]. There is another relationship that links agriculture, health, and care: maternal nutrition and health status is the basis of a mother's ability to care for her children. However, industrialized food systems can negatively affect reproductive health through the intensive use of pesticides, chemical fertilizers, hormones, antibiotics, and fossil fuels in food production, as well as chemicals in food packaging. During the times of conception through pregnancy, infancy, childhood, and puberty, humans are more susceptible to harm from nutrition and the environment. Pregnant women in the United States, for example, were widely exposed to agricultural pesticides primarily from food, water, and soil. This can for instance harm the developing brain of the baby, which may adversely impact child mental and behavioral development [62]. In a similar manner, other food system-associated diseases such as described by McDermott and Grace [32] can decrease the ability of mothers and other caregivers to care for their children if their health status is adversely impacted. Thus, to ensure healthy pregnancies, children, and future generations, these links need to be examined as well. However, almost none of these trade-offs in agriculture and changing food systems that negatively influence care practices are described in any literature found about nutrition-sensitive agriculture. Only Herforth et al. [26] discussed how 
agriculture in developing countries possibly influences care practices for children:

- Consistent access to diverse diets for pregnant and lactating women as well as young children

- Production of nutrient-dense complementary foods

- Water supply and quality

- Exposure to insect vectors, zoonotic disease, and contaminants in agrochemicals

- Physical work during pregnancy

- Mother's labor and time spent on agriculture without available childcare components

- Coordination with health and social protection programs

They concluded that beside time-saving technologies, it is the key to strengthen women's decision-making power and control of economic resources as well as support women's income generation with policies to facilitate high-quality child care [26]. Although the factors empowerment of women and income of women got slightly more votes in the survey than care, the significance that women have on nutrition $[8,16,28]$ seemed not to get the awareness of agricultural politicians that is needed. Moreover, scientific analyses of the role of women in the pathways from agriculture to improved nutrition tended to focus on the constraints women face to raising agricultural yields and the improved productivity of women and earnings while ignoring care issues [58].

Besides the potential for agriculture to improve household food security, it is critically important that care aspects be analyzed and that the manner in which agriculture and food systems might enhance or diminish caregiving environments, resources, and capacities be taken into consideration $[58,59]$. However, literature showing the negative impacts on nutrition was limited, and empirical studies on the links need to be updated [63]. Therefore, current good caring practices, how they might be threatened by new influences on the food system and how they might be protected in changing, modernizing, and urbanizing societies need to be investigated [61] if agriculture and the food system want to be truly nutrition-sensitive.

\section{A comprehensive definition of nutrition-sensitive agriculture}

The results of the survey show that a commonly accepted definition and aim of nutrition-sensitive agriculture did not exist at the time of data analysis. This nonexistent common understanding of nutrition-sensitive agriculture was mentioned as one of the factors that hinder agricultural ministries from implementing it. In the literature, the key recommendations for improving nutrition through agriculture were described as principles that "usefully articulate what nutrition-sensitive agriculture is" [64] and as a "well-vetted current consensus among development partners" [64]. It seems that nutrition-sensitive agriculture is seen as a strategy for developing countries. However, considering the fact that agriculture and food systems are the basis for nutrition all over the world, they should be nutrition-sensitive in every country, regardless of their development status or which malnutrition problems exist there. Recently, the key recommendations were broadened to include improving nutrition through agriculture and food systems [65]. The recommendations still contain ten principles. They refer mainly to food security aspects; however, they also mention the consideration of potential harm. Dury et al. [63] reviewed the current literature and conducted expert interviews on the potential negative outcomes of agricultural production on nutrition. Their assessment identified six categories of risks according to the six impact pathways between agriculture and nutrition. These risks are related to sources of income, food availability, price ratios, women's social status and workload, health risks, environmental degradation, and inequalities. According to their risk analysis, they developed five principles:

1. Identify and keep track of nutritional risks throughout the life span of the intervention.

2. Promote diversification to prevent risks linked to specialization of farming systems and incomes.

3. Encourage practices with low labor requirements and activities enabling women to increase their autonomy.

4. Set in place good practices known to enable a reduction in health risks.

5. Anticipate potential exclusion effects of interventions, and pay specific attention to vulnerable groups.

Taking this together, a system-oriented definition becomes necessary. To consider nutrition-sensitive agriculture as a new comprehensive concept, all underlying determinants of malnutrition according to the UNICEF conceptual framework have to be considered along the whole value chain. Therefore "nutrition-sensitive agrifood systems" would be a better term and should be defined as follows:

Nutrition-sensitive agrifood systems help improve the nutritional status and health of a population in the long term by improving the underlying determinants of adequate nutrition, in particular by increasing the availability, access, and consumption of food that meets people's nutrition needs and by minimizing the unintended negative nutritional consequences on health and care along the value chain in order to combat all forms of malnutrition and in the end achieve healthy, sustainable diets. 
However, at the ICN2, an FAO fact sheet was handed out that defined nutrition-sensitive agriculture as "a food-based approach to agricultural development that puts nutritionally rich foods, dietary diversity, and food fortification at the heart of overcoming malnutrition and micronutrient deficiencies (...) The overall objective of nutritionsensitive agriculture is to make the global food system better equipped to produce good nutritional outcomes" [66]. Thus, they defined three main areas:

1. Making food more available and accessible

2. Making food more diverse and production more sustainable

3. Making food itself more nutritious

This description focuses on food security and includes neither health nor care aspects, nor potential risks as discussed above.

With the ICN2, political commitment for nutrition should be renewed. Representatives from more than 170 governments participated in the conference [5]. On 19 November, they endorsed the outcome documents-the Rome Declaration on Nutrition and the Framework for Action. Looking into the documents, nutrition-sensitive agriculture is mentioned only once in recommendation 8 of the Framework for Action under the headline "Recommended actions for sustainable food systems promoting healthy diets" [67]:

Review national policies and investments and integrate nutrition objectives into food and agriculture policy, programme design and implementation, to enhance nutrition sensitive agriculture, ensure food security and enable healthy diets.

In the Rome Declaration, the term itself is not mentioned, but one commitment to action is made that includes some of the elements mentioned above [68]:

15 c) enhance sustainable food systems by developing coherent public policies from production to consumption and across relevant sectors to provide year-round access to food that meets people's nutrition needs and promote safe and diversified healthy diets;

This indicates that nutrition-sensitive agriculture is becoming more important. However, as described above, FAO does not communicate it as the comprehensive concept that considers all underlying determinants of malnutrition according to the UNICEF conceptual framework. Moreover, the commitments of action in the Rome Declaration focus on food security aspects. That seems to confirm the findings in this study: the awareness and understanding of nutrition-sensitive agriculture as a comprehensive concept is still scarce among politicians. In general, one complaint is that ICN2 focuses too much on food aspects and does not sufficiently refer to the other underlying causes, care, and health [69]. Studies (e.g., [70, 71]) showed that food-based approaches were only effective in improving nutrition if they had an integral approach that considered health and care issues. Moreover, Haddad and Isenman [72] argued that focus should be on interventions that affect not only the underlying determinants but also the basic determinants.

\section{Limitations}

When interpreting the answers collected in the questionnaire-based survey, one must keep in mind that the survey was underpowered. Only 18 questionnaires could be analyzed. Because of the small sample size, statistical significance tests are questionable and were only done very carefully to complement the descriptive analysis. Thus, they cannot be interpreted in isolation. Additionally, cluster analysis was seen as an explorative process that can uncover underlying structures. The clustering here should be interpreted very carefully, especially because of the small sample size compared to the amount of variables. Moreover, representatives of industrialized countries did not explicitly state whether they were working on agriculture in their own countries or providing agricultural support to developing countries. However, the GFFA has a focus on food and nutrition security, so the representatives of the industrial countries were most likely working in the field of global food and nutrition security.

Beside agricultural politicians' low interest in nutritionsensitive agriculture, reasons for the low number of responses could be the limited time available for a scientific study at the GFFA. The delegations had arranged a lot of bilateral meetings with other delegations in advance or had arrived only on Saturday for the summit. The timetables of the delegations were therefore very packed, leaving little time to introduce the survey. Furthermore, the low response rate could be attributed to the fact that the term "nutrition-sensitive agriculture" was fairly new at the time of the survey. This may especially deter representatives who have not previously heard about it. Looking at the countries with representatives that responded, five of them had been participating in the SUN collaborative process and three were donor countries. That means that about $44 \%$ of the countries with representatives that participated in the survey were involved in SUN. This can be interpreted as a special interest in nutrition and nutritionrelated topics. Therefore, a possible systematic bias is that agricultural ministries that are particularly interested in nutrition were more likely to have participated in the study. However, no difference in the answers could be 
found contingent upon their engagement in SUN. Looking at the other country characteristics, they were not representative of most developing or industrial countries. Most were smaller countries, and none of the industrial countries were assumed to have an obesity problem. Furthermore, most of the ministers that attended GFFA 2014 were from countries that are geographically close to Germany and/or were financially able to travel to Germany. Therefore, results cannot be generalized for all countries. However, as only limited data on the political commitment to nutrition are available in the literature, this study gave some valuable insights into the interest of agricultural politicians for nutrition-sensitive agriculture. Moreover, it presents a way for qualitative data to become an important source for a deeper understanding of the political commitment to nutrition. The mixed methods approach combining a survey based on a literature review and the qualitative content analysis according to Mayring especially complemented each other and gave overall a good basis for finding an answer to the question of whether nutrition-sensitive agriculture is only a new term or a new actionable concept with a comprehensive definition and framework as well as political will.

\section{Conclusion}

Little interest in taking part in the survey as well as almost no inclusion of nutrition-sensitive agriculture or elements of nutrition-sensitive agriculture in the communiqué indicates that political commitment to nutrition-sensitive agriculture by agricultural politicians was small. Care issues were less considered in the survey and not at all in the communiqué. Health aspects regarding food safety were the primary consideration in the survey and communiqué. Thus, a comprehensive understanding was missing at the time of the study and, as previously discussed, also at the Second International Conference on Nutrition (ICN 2). In conclusion, these findings indicate that political understanding and commitment in agricultural ministries to nutrition-sensitive agriculture beyond food security as a system approach were scarce. Thus, nutritionsensitive agriculture seems to be more of a term than a concept. To enhance its understanding, especially in politics, a holistic definition of nutrition-sensitive agrifood systems as well as a precise and clear communication strategy is needed. If ICN 2 wants to count over the next years, the interlinkages between different sectors have to be taken into account. That means for agriculture and food systems to consider potential risks of agricultural and food programs and policies to nutrition through negative side effects on care and health aspects and find ways to address them. With the current emphasis on nutrition, a window of opportunity exists to promote nutrition-sensitive cross-sectoral strategies. However, efforts to communicate nutritionsensitive agriculture and food systems as the system approach that encompasses all underlying causes of malnutrition in their interrelatedness and complexity along the whole value chain must be significantly increased. Such an understanding is especially needed for a sustainable development goal concerning nutrition such as eradicating malnutrition in all its forms through sustainable food systems.

\section{Additional file}

Additional file 1: Questionnaire used for the survey at the GFFA 2014.

\section{Abbreviations}

BMEL: Federal Ministry of Food and Agriculture of Germany; EU: European Union; FAO: Food and Agriculture Organization of the United Nations; GFFA: Global Forum for Food and Agriculture; HANCl: Hunger and Nutrition Commitment Index; ICN2: Second International Conference on Nutrition; IFPRI: International Food Policy Research Institute; IGW: International Green Week; IYCF: Infant and Young Child Feeding; SDG: Sustainable Development Goal; SUN: Scaling Up Nutrition; UN: United Nations; UNEP: United Nations Environment Programme; UNICEF: United Nations International Children's Emergency Fund; UNSCN: United Nations Standing Committee on Nutrition; WHO: World Health Organization of the United Nations.

\section{Competing interests}

The authors declare that they have no competing interests.

\section{Authors' contributions}

$A B$ assessed, analyzed, and interpreted the data. She drafted the manuscript with the contribution of $\mathrm{EH}$ who also added to the content analysis of the final communiqué and IJ who assisted in designing the overall study. All authors have read and approved the final version of the manuscript.

\section{Acknowledgements}

The authors thank the Federal Ministry of Food and Agriculture of Germany for its support to Angelina Balz in supporting data collection and providing her an internship for 6 months. Our thanks go also to Dr. Johannes Herrmann who assisted in data analysis and to Professor Michael B. Krawinkel for his mentoring before, during, and after the study.

Received: 1 February 2015 Accepted: 6 May 2015

Published online: 21 May 2015

\section{References}

1. FAO (Food and Agriculture Organization of the United Nations). Food and nutrition in numbers 2014. Rome: Food and Agriculture Organization of the United Nations; 2014.

2. FAO (Food and Agriculture Organization of the United Nations). The state of food and agriculture food systems 2013: food systems for better nutrition. Rome: Food and Agriculture Organization of the United Nations; 2013.

3. Albrecht S. Future of food: state of the art, challenges and options for action. München: oekom; 2013.

4. HLPEP (High-Level Panel of Eminent Persons). A new global partnership: eradicate poverty and transform economies through sustainable development. In: The report of the high-level panel of eminent persons on the Post-2015 Development Agenda. 2013. http://www.susana. org/_resources/documents/default/2-1930-hlp-reportenglish-access-pdf.pdf. Accessed 20 Nov 2014

5. FAO (Food and Agriculture Organization of the United Nations). Second International Conference on Nutrition (ICN2): Better nutrition better lives. http://www.fao.org/about/meetings/icn2/en/ (2015). Accessed 2 Jan 2015.

6. Levinson FJ, Balarajan Y. Addressing malnutrition multisectorally: what have we learned from recent international experience?: UNICEF 
Nutrition Working Paper. 2013. http://www.mdgfund.org/sites/default/ files/Addressing\%20malnutrition\%20multisectorally-FINAL-submitted.pdf. Accessed 26 Feb 2014.

7. World Bank. Improving nutrition through multisectoral approaches. 2013 http://www-wds.worldbank.org/external/default/WDSContentServer/ WDSP/IB/2013/02/05/000356161_20130205130807/Rendered/PDF/ 751020WPOImpro00Box374299B00PUBLIC0.pdf. Accessed 26 Feb 2014.

8. Ruel MT, Alderman H. Nutrition-sensitive interventions and programmes: how can they help to accelerate progress in improving maternal and child nutrition? Lancet. 2013;382(9891):536-51.

9. UNICEF. Strategy for improved nutrition of children and women in developing countries. New York: United Nations Children's Fund; 1990.

10. Mayring P. Qualitative Inhaltsanalyse: Grundlagen und Techniken. 11th ed. Beltz: Weinheim; 2010.

11. Mayring P. Qualitative content analysis: theoretical foundation, basic procedures and software solution. Klagenfurt; 2014. URN: http://nbnresolving.de/urn:nbn:de:0168-ssoar-395173.

12. BMEL (Bundesministerium für Ernährung und Landwirtschaft). Review of the GFFA 2014. Empowering Agriculture: Fostering Resilience - Securing Food and Nutrition. http://www.gffa-berlin.de/en/review-gffa/359-rueckblick2014.html (2014). Accessed 24 Feb 2014

13. Jaenicke $H$, Virchow D. Entry points into a nutrition-sensitive agriculture. Food Sec. 2013;5(5):679-92

14. Kriesemer SK. Nutrition-sensitive agriculture: the conceptual framework underlying a new (?) approach. In: Virchow D, editor. Nutrition-sensitive agriculture: a pillar of improved nutrition and better health. 2013. p. 76-101. https:/ew.uni-hohenheim.de/fileadmin/einrichtungen/fsc/Research_projects/ Nutrition-sensitive_agriculture___FSC___xxx.pdf. Accessed 13 Nov 2013.

15. Swaminathan MS. The cooperative pathway of enhancing rural livelihood and nutrition security. Int J Rural Manage. 2013;9(1):1-15.

16. World Bank. Improving nutrition through multisectoral approaches: agriculture and rural development. 2013. https:/openknowledge.worldbank.org/bitstream/ handle/10986/16953/751030BRIOImpr00Box374299B00PUBLICO.pdf?sequence=1 Accessed 26 Feb 2014.

17. FAO (Food and Agriculture Organization of the United Nations). Nutritionsensitive agriculture and food-based approaches. http://www.fao.org/food/ nutrition-sensitive-agriculture-and-food-based-approaches/food-based-approach/food-based-approach/en/ (2014). Accessed 8 Mar 2014.

18. Ag2Nut CoP (Agriculture-Nutrition Community of Practice). Key recommendations for improving nutrition through agriculture. 2013. http://unscn.org/files/Agriculture-Nutrition-CoP/Agriculture-Nutrition_ Key_recommendations.pdf. Accessed 5 Nov 2013.

19. FAO (Food and Agriculture Organization of the United Nations). Synthesis of guiding principles on agriculture programming for nutrition. 2013. http://www.fao.org/docrep/017/aq194e/aq194e.pdf. Accessed 8 Mar 2014.

20. Thompson B, Amoroso L. Combating micronutrient deficiencies: food-based approaches. Rom: FAO (Food and Agriculture Organization of the United Nations); CAB International; 2011.

21. Traoré $\mathbf{M}$, Thompson $B$, Thomas $G$. Sustainable nutrition security: restoring the bridge between agriculture and health. Food and Agriculture Organization of the United Nations: Rome; 2012

22. Powell B, Ickowitz A, McMullin S, Jamnadass R, Padoch C, Pinedo-Vasquez $M$, et al. The role of forests, trees and wild biodiversity for nutrition-sensitive food systems and landscapes. 2013. http://www.fao.org/fileadmin/user_upload/ agn/pdf/2pages_Powelletal.pdf. Accessed 8 Mar 2014.

23. Welch RM, Graham RD, Cakmak I. Linking agricultural production practices to improving human nutrition and health. 2013. http://www.fao.org/fileadmin/ user_upload/agn/pdf/WelchICN21edit_1 July_01.pdf. Accessed 15 Mar 2014.

24. Ladd KD. Designing nutrition-sensitive agriculture activities. 2013. http://www.fao.org/fileadmin/user_upload/agn/pdf/DesigningNutSensAgriActivities.pdf. Accessed 4 Mar 2014.

25. Keding GB, Cogill B. Linking nutrition and agrobiodiversity. 2013 http://www.fao.org/fileadmin/user_upload/agn/pdf/KedingandCogill_ paper_1July.pdf. Accessed 28 Oct 2013.

26. Herforth A, Jones A, Pinstrup-Andersen P. Prioritizing nutrition in agriculture and rural development: guiding principles for operational investments, HNP Discussion Paper. 2012. https://openknowledge.worldbank.org/bitstream/ handle/10986/13571/NonAsciiFileName0.pdf?sequence=1. Accessed 11 Nov 2013

27. CGIAR (Consultative Group on International Agriculture Research). Agriculture for improved nutrition \& health: CGIAR Research Program 4.
2011. www.ifpri.org/sites/default/files/crp4proposal_final_oct06_2011.pdf. Accessed 18 Mar 2014

28. Beuchelt TD, Badstue L. Gender, nutrition- and climate-smart food production: opportunities and trade-offs. Food Sec. 2013:5(5):709-21.

29. Fan S, Pandya-Lorch R, editors. Reshaping agriculture for nutrition and health. Washington: International Food Policy Research Institute; 2012.

30. Gillespie S, Kadiyala S. Exploring the agriculture-nutrition disconnect in India. In: Fan S, Pandya-Lorch R, editors. Reshaping agriculture for nutrition and health. Washington: International Food Policy Research Institute; 2012. p. 173-81.

31. Hawkes C, Ruel MT, Value chains for nutrition. In: Fan S, Pandya-Lorch R, editors. Reshaping agriculture for nutrition and health. Washington: International Food Policy Research Institute; 2012. p. 73-82.

32. McDermott J, Grace D. Agriculture-associated diseases: adapting agriculture to improve human health. In: Fan S, Pandya-Lorch R, editors. Reshaping agriculture for nutrition and health. Washington: International Food Policy Research Institute; 2012. p. 103-11.

33. Hoddinott J. Agriculture, health, and nutrition: toward conceptualizing the linkages. In: Fan S, Pandya-Lorch R, editors. Reshaping agriculture for nutrition and health. Washington: International Food Policy Research Institute; 2012. p. 13-20.

34. Pinstrup-Andersen P. The food system and its interaction with human health and nutrition. In: Fan S, Pandya-Lorch R, editors. Reshaping agriculture for nutrition and health. Washington: International Food Policy Research Institute; 2012. p. 21-9.

35. Pinstrup-Andersen P. Overview of nutrition sensitive food systems: policy options and knowledge gaps. 2013. http//www.fao.org/fileadmin/user_upload/ agn/pdf/NutSensitiveFoodSystems_FINAL.pdf. Accessed 21 Nov 2013.

36. Hawkes C, Turner R, Waage J. Current and planned research on agriculture for improved nutrition: a mapping and a gap analysis: a report for DFID. 2012. http://r4d.dfid.gov.uk/pdf/outputs/misc_susag/LCIRAH_mapping_ and_gap_analysis_21Aug12.pdf. Accessed 8 Dec 2013.

37. Turner R, Hawkes C, Waage J, Ferguson E, Haseen F, Homans H, et al. Agriculture for improved nutrition: the current research landscape. Food Nutr Bull. 2013;34(4):369-77.

38. Girard AW, Self JL, McAuliffe C, Olude O. The effects of household food production strategies on the health and nutrition outcomes of women and young children: a systematic review. Paediatr Perinat Epidemiol. 2012;26:205-22.

39. Masset E, Haddad L, Cornelius A, Isaza-Castro J. Effectiveness of agricultural interventions that aim to improve nutritional status of children: systematic review. BMJ. 2012. doi:10.1136/bmj.d8222.

40. Hammond RA, Dube L. A systems science perspective and transdisciplinary models for food and nutrition security. Proc Natl Acad Sci. 2012;109(31):12356-63

41. Garnett T. Food sustainability: problems, perspectives and solutions. Proc Nutr Soc. 2013;72(01):29-39.

42. Lang T. Reshaping the food system for ecological public health. J Hunger Environ Nutr. 2009;4(3-4):315-35.

43. Keding GB, Schneider K, Jordan I. Production and processing of foods as core aspects of nutrition-sensitive agriculture and sustainable diets. Food Sec. 2013;5(6):825-46.

44. Chung K. An introduction to nutrition-agriculture linkages. 2012. http://www.spring-nutrition.org/introduction-nutrition-agriculture-linkages. Accessed 5 Mar 2014.

45. Webb P. Impact pathways from agricultural research to improved nutrition and health: literature analysis and research priorities. 2013. http://www.fao.org/fileadmin/user_upload/agn/pdf/Webb_FAO_paper_ Webb_June_26_2013_pdf. Accessed 21 Dec 2013.

46. Kurz K. Nutrition-enhancing interventions and agriculture value chains: preliminary lessons from feed the future implementation in four countries. 2013. http://www.fao.org/fileadmin/user_upload/agn/pdf/Kurz-DAl_FAOpaper1July.pdf. Accessed 28 Oct 2013.

47. Dangour AD, Green R, Häsler B, Rushton J, Shankar B, Waage J. Linking agriculture and health in low- and middle-income countries: an interdisciplinary research agenda. Proc Nutr Soc. 2012;71(02):222-8.

48. Thompson B, Meerman J. Narrowing the nutrition gap: investing in agriculture to improve dietary diversity. 2013. http://www.fao.org/fileadmin/user_upload/ agn/pdf/Narrowing_Nutrition_Gap_2013.pdf. Accessed 24 Nov 2013.

49. Waage J, Dangour AD, Hawkesworth S, Johnston D, Lock K, Poole N, et al. WP 1: Understanding and improving the relationship between agriculture and health: Foresight project on global food and farming future. 2011. 
http://www.lcirah.ac.uk/_assets/Foresight\%20Report\%20Agriculture\%20and\% 20Health\%2Oreview.PDF. Accessed 8 Mar 2014.

50. Beuchelt TD. Can nutrition-sensitive agriculture be successful without being gender-sensitive?: A human rights perspective. In: Virchow D, editor. Nutrition-sensitive agriculture: a pillar of improved nutrition and better health. 2013. p. 102-52. https:/ew.uni-hohenheim.de/fileadmin/einrichtungen/ fsc/Research_projects/Nutrition-sensitive_agriculture___FSC_-_xxx.pdf. Accessed 13 Nov 2013.

51. Flick U. Sozialforschung: Methoden und Anwendungen. Ein Überblick für die BA-Studiengänge. Rowohlt Taschenbuch: Reinbek; 2009.

52. Cohen J. Things I, have learned (so far). Am Psychol. 1990;45(12):1304-12.

53. Gigerenzer $\mathrm{G}$, Krauss $\mathrm{S}$, Vitouch $\mathrm{O}$. The null ritual: what you always wanted to know about significance testing but were afraid to ask. In: Kaplan $D_{\text {, }}$ editor. The Sage handbook of quantitative methodology for social sciences. Thousan Oaks, CA: Sage; 2004. p. 391-408.

54. Kühnel S, Krebs D. Statistik für die Sozialwissenschaften: Grundlagen, Methoden, Anwendungen. 5th ed. Reinbek bei Hamburg: RowohltTaschenbuch-Verl; 2010.

55. Gillespie S. Nutrition policy and practice: unpacking the politics. In: IFPRI (International Food Policy Research Institute), editor. Global Food Policy Report. Washington DC: International Food Policy Research Institute. 2013;2014:75-85

56. te Lintelo DJ, Haddad L, Lakshman R, Gatellier K. The Hunger and Nutrition Commitment Index (HANCI 2012): measuring the political commitment to reduce hunger and undernutrition in developing countries. 2013. http://www.hancindex.org. Accessed 20 May 2014.

57. IDS (Institute of Development Studies). HANCI infographics. 2014. http://www.hancindex.org/explore-the-data/hanci-infographics/ \#.U5cuZHbzPgk. Accessed 6 May 2014.

58. Jones AD, Cruz Agudo Y, Galway L, Bentley J, Pinstrup-Andersen P. Heavy agricultural workloads and low crop diversity are strong barriers to improving child feeding practices in the Bolivian Andes. Soc Sci Med. 2012;75(9):1673-84.

59. Jones AD. The production diversity of subsistence farms in the Bolivian Andes is associated with the quality of child feeding practices as measured by a validated summary feeding index. Public Health Nutr. 2015;18(2):329-42.

60. Wyatt AJ, Yount KM, Null C, Ramakrishnan U, Girard AW. Dairy intensification, mothers and children: an exploration of infant and young child feeding practices among rural dairy farmers in Kenya. Matern Child Nutr. 2015;11(1):88-103.

61. Latham MC. Human nutrition in the developing world. Rome: FAO (Food and Agriculture Organization of the United Nations); 1997.

62. Sutton P, Wallinga D, Perron J, Gottlieb M, Sayre L, Woodruff T. Reproductive health and the industrialized food system: a point of intervention for health policy. Health Aff. 2011;30(5):888-97.

63. Dury S, Alpha A, Bichard A. What risks do agricultural interventions entail for nutrition?: working paper - umr moisa. 2014. https://www.spring-nutrition.org/ sites/default/files/dury_alpha_bichard_2014_risks_agric_acf.pdf. Accessed 27 May 2014.

64. Herforth A, Dufour C. Key recommendations for improving nutrition through agriculture: establishing a global consensus. In: UNSCN (United Nations Standing Committe on Nutrition), editor. Changing food systems for better nutrition; SCN News No 40. 40th ed. 2014. p. 33-8.

65. Ag2Nut CoP (Agriculture-Nutrition Community of Practice). Key recommendations for improving nutrition through agriculture and food systems. 2014. http://unscn.org/files/Agriculture-Nutrition-CoP/AgricultureNutrition_Key_recommendations.pdf. Accessed 29 Dec 2014.

66. FAO (Food and Agriculture Organization of the United Nations). Second International Conference on Nutrition 19-21 November 2014: Nutritionsensitive agriculture. Rome: FAO (Food and Agriculture Organization of the United Nations); 2014.

67. FAO and WHO (Food and Agriculture Organization of the United Nations and World Health Organization). Second international conference on nutrition. In: Conference outcome document: framework for action. 2014. http://www.fao.org/3/a-mm215e.pdf. Accessed 6 Jan 2015.

68. FAO and WHO (Food and Agriculture Organization of the United Nations and World Health Organization). Second international conference on nutrition. In: Conference outcome document: Rome declaration on nutrition. 2014. http://www.fao.org/3/a-ml542e. Accessed 6 Jan 2015

69. Wijeratna A, Hauenstein Swan S. Action to improve nutrition: making ICN2 count over the next decade and beyond. 2014. http://www.unscn.org/files/ Announcements/ACF-ImproveNutritionMakingICN2Cont-Nov14-final.pdf. Accessed 29 Dec 2014
70. Lewis CJ. The Gender Informed Nutrition and Agriculture (GINA) Alliance and the Nutrition Collaborative Research Support Program (NCRSP). In: Thompson B, Amoroso L, editors. Improving diets and nutrition: food-based approaches. Wallingford: CABI; 2014. p. 113-23.

71. Adrianopoli M, D'Acapito P, Ferrari M, Mistura L, Toti E, Maiani G, et al. Optimized feeding recommendations and in-home fortification to improve iron status in infants and young children in the Republic of Tajikistan: a pilot project. In: Thompson B, Amoroso L, editors. Improving diets and nutrition: food-based approaches. Wallingford: CABI; 2014. p. 230-45.

72. Haddad L, Isenman P. Which aid spending categories have the greatest untapped potential to support the reduction of undernutrition? Some ideas on moving forward. Food Nutr Bull. 2014;35(2):266-76.

73. Krawinkel MB, Keding GB, Chavez-Zander U, Jordan I, Habte T. Welternährung im 21. Jahrhundert: Eine umfassende Herausforderung (Teil 2). Biol Unserer Zeit. 2008;6(38):382-9.

74. BMZ (Bundesministerium für wirtschaftliche Zusammenarbeit und Entwicklung). DAC-Liste der Entwicklungsländer und -gebiete (gültig für die Berichtsjahre 2011-2013). http://www.bmz.de/de/ministerium/zahlen_fakten/ hintergrund/dac_laenderliste/index.html (2014). Accessed 23 Mar 2014.

75. WHO (World Health Organization). Health conditions in the occupied Palestinian territory, including east Jerusalem, and in the occupied Syrian Golan: sixty-sixth world health assembly, Provisional agenda item 20. 2012. http:/apps.who.int/gb/ ebwha/pdf_files/WHA65/A65_27Rev1-en.pdf. Accessed 23 Mar 2014.

\section{Submit your next manuscript to BioMed Central and take full advantage of:}

- Convenient online submission

- Thorough peer review

- No space constraints or color figure charges

- Immediate publication on acceptance

- Inclusion in PubMed, CAS, Scopus and Google Scholar

- Research which is freely available for redistribution 